\title{
Analysis of the NPT effect in women with chronic LBP: a pilot study
}

\author{
Phillipe Villeneuve1, Lisandro Antonio Ceci', Rodolfo Borges Parreira', Larissa Gulogurski Ribeiro², \\ Andressa Panegalli Hosni², Marcos Paulo Polowei Rolão², Jossinelma Camargo Gomes², Thais Barbosa De Oliveira², \\ Mário Cesar da Silva Pereira ${ }^{3}$, Afonso Shiguemi Inoue Salgado', Ivo Ilvan Kerppers ${ }^{3}$
}

\begin{abstract}
Introduction: low back pain (LBP) is characterized by pain in the region between the last costal arches and the gluteal fold. It can occur due to several intrinsic and extrinsic factors, and it has a very high prevalence in adulthood, causing several problems which directly influence the quality of life. Neurosensory Postural Therapy (NPT) is a technique which uses manual neural stimulation to adjust muscle tone. Objective: The aim of the present study was to verify the effects of NPT on pain, mobility, flexibility, functionality, cardiac variability and body oscillation. Methodology: Seven women over 20 years old were recruited, which were evaluated before and after the technique, which consisted of pressure on the upper and lower roots of the sciatic nerve at 3 points for 60 seconds. Results: The mean pain score was $2.71 \pm 1.38$ and $1.35 \pm 1.18$, with a value of $p=0.02$. For the Schöber test we obtained a mean of $21.93 \pm 1.36$ and $22.34 \pm 1.30 \mathrm{~cm}$ in the pre- and post-test with $p=0.01$. No statistical difference was found in the Rolland Morris questionnaire. The electromyography obtained statistical difference in the analysis of the gluteus medius with $p=0.02$. Significant results $(p=0.0001)$ were found in the lateral evaluation by the stabilometry and the HF/LF ratio showed difference with $p=0.03$ in the pretest and after 30 days. Conclusion: The technique of NPT has benefits in the parameters studies, demonstration being a fast technique with period of efficiency.
\end{abstract}

Keywords: Pain; Flexibility; Muscle Activation, Cardiac Variability.

\section{INTRODUCTION}

Low Back Pain (LBP) is characterized by pain in the lower back region between the last costal arches and the gluteal fold. This dysfunction may be classified into acute, subacute or chronic, and also according to the specific etiologic diagnosis when it has definite or nonspecific cause or when there is no known cause. It is estimated that $75-90 \%$ of the costs are intended for patients with chronic $L B P^{(1)}$.

LBP may lead to decreased amplitude, flexibility, mobility and coordination of movements, increased fatigue and trunk instability, and psychological changes which directly affect the individual's functioning, and consequently his quality of life ${ }^{(2)}$.

Among the several treatments for LBP, a typical technique is Neurosensory Postural Therapy (NPT), derived from clinical posturology developed by Gagey and Weber in the $70^{\prime} \mathrm{s}^{(3)}$, that uses the manual neural stimulation in order to adapt the Muscle tone impaired by functional disorders resulting from postural changes.

It is very important to investigate new and effective conducts to treat $L B P$, verifying the effectiveness and functionality, expanding the therapeutic options, and consequently improving the quality of life of people with chronic LBP. The present study aims to evaluate the effects of the NPT technique on pain, mobility, flexibility, functionality, heart rate variability, weight distribution and muscle activation in women with chronic LBP.

\section{MATERIALS AND METHOD}

\section{Subjects}

07 women with non-specific chronic LBP were evaluated, age over 20 years, mean age of 21.85 years, before and after the application of the technique. Inclusion criteria were presenting symptom of LBP for more than 12 weeks and clinical and physical characteristics compatible with category 1 and 2 of the evaluation and treatment guidelines proposed by the American College of Physicians (ACP) and the American Pain Society ${ }^{(4)}$. The study followed the norms and standards of the Ethics Committee of the Unicentro (COMEP) and was approved under protocol No. 1,288,148/2015. All participants signed the Free and Informed Consent Term.

\footnotetext{
Corresponding author: Jossinelma Camargo Gomes Rua Júlio de Castilhos, number 1410, CEP 85040-170, bairro: Vila Carli, Guarapuava / PR, Brasil jossinelma@hotmail.com

2 Student of the Universidade Estadual do Centro-Oeste (UNICENTRO), Laboratory of Neuroanatomy and Neurophysiology, Guarapuava (PR), Brazil. Full list of author information is available at the end of the article.
}

Financial support: None. 
As exclusion criteria, were adopted the presence of severe pathologies in the column (fractures, tumors and inflammatory pathologies such as ankylosing spondylitis), impaired nerve root (disc hernia, spondylolisthesis with nervous impairment, spinal stenosis, among others), severe cardiorespiratory disease and pregnancy.

\section{Procedures}

\section{Manual Neural Stimulation}

For manual neural stimulation, the individual remained in the prone position with the head in the midline and the therapist adjacent to the individual performing the motor territories tests of possible innervation involved in the symptomatic status of the patient. After detected dysfunctional territory, it was known the corresponding nerve and then it was performed a manual neural stimulation in a direct or indirect access point of the nerve (stimulation point), and standardized application on the right side once.

The dysfunctional innervation evaluation occurred in accordance with the description of Villeneuve $(2012)^{(5)}$ where the muscles related to a nerve dysfunction is in changing of its tonic state. For the present study, it was selected the gluteal and gluteal nerve.

The location of the stimulation point of the gluteal nerve is about $5 \mathrm{~cm}$ medial to the major trochanter of the femur in the division between the upper border of the piriformis and the lower border of the gluteus minimum ${ }^{(6)}$. The motor territory of that nerve are the gluteus medius, minimum and tensor fascia latae ${ }^{(7)}$. To locate the point of stimulation in the inferior gluteal nerve, $5 \mathrm{~cm}$ medially from the greater trochanter of the femur is measured, with the emergence of the nerve between the inferior border of the piriformis muscle and the superior border of the superior gemellus. And its motor territory is the gluteus maximus muscle ${ }^{(8)}$.

The technique procedure was performed in order to locate which nerve presents dysfunction by checking differences in muscle tone. When investigating the tonus of muscles related to the nerves in focus in this study, it was verified which muscle showed a reduction of the tonus, indicating the nerve to be stimulated. Keeping one hand on the muscular territory of the dysfunctional nerve and perceiving the tonus, a slow and progressive pressure was performed with the thumb of the other hand on the stimulation point of the corresponding nerve until a normalization of the tonus was perceived in the muscular territory. At this point, the thumb of the other hand which was on the motor territory that is making the pressure. Afterward, the fingers were removed in a fast supination movement of the wrists. The technique was applied in the right gluteus region and only one application according Figure 1.

\section{Evaluation tools}

\section{Numerical pain scale}

The patients had pain evaluated before and after the technique application through the numerical scale of pain. This scale evaluates the level of pain intensity perceived by the patient using a horizontal scale of 100 millimeters ( 0 = no pain, $100=$ worst imaginable pain), where the patient reports the degree of LBP during the evaluation. The numerical scale of pain has an excellent metric property, it is easy to apply and punctuate and it has been widely used in researches in $\mathrm{LBP}^{(9)}$.

\section{Schöber Test}

Schober test was used for measurement of lumbar motion. The test is performed in standing position with maximum flexion of the spine anteriorly with the extended knees. With the participant in orthostatic position, horizontal lines are drawn $10 \mathrm{~cm}$ above and $5 \mathrm{~cm}$ below the lumbosacral junction. The test was considered normal when there was a variation of five or more centimeters between the measurements in the orthostatic position and with the flexed torso. The test was performed three times in each participant, adopting the mean value obtained from the three measurements ${ }^{(10)}$.

\section{Wells Bench}

Flexibility was assessed by the Wells test and Dillon, using a "Wells bench", consisting of a wooden box with dimensions of $30.5 \times 30.5$ centimeters, with the flat top 56.5 centimeters in length, in which is fixed a tape. The participants sat with their legs outstretched and barefoot, resting fully on the box with one hand over the other, keeping their indicators fingers together, superimposed and aligned and resting on the flat surface of the box. Subsequently, with the extended knees, they flexed the spine with the head between the arms until the maximum range of motion, remaining static for approximately two seconds, so that the evaluator could record the reading on the scale. Three measures were taken, adopting the highest value ${ }^{(11)}$.

\section{Rolland-Morris Inability Questionnaire}

The Rolland-Morris questionnaire assesses the disability associated with LBP through 24 questions which describe the daily tasks in which patients have difficult to perform

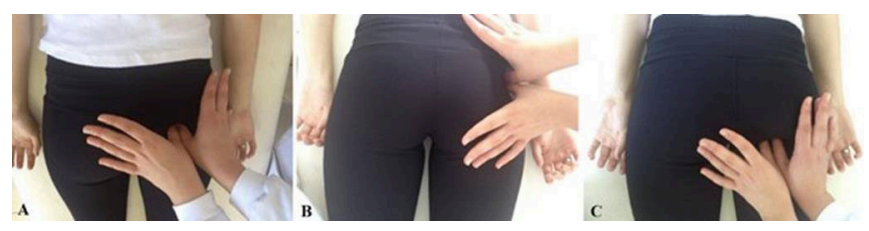

Figure 1. Finger positioning on the superior gluteal nerve and its branches. 
it due to LBP. The patients were instructed to answer the questions which apply to them corresponding to the last 24 hours. The questionnaire was adapted and validated by Nusbaum et al. (2001)(12) where it shown to be reproducible and valid when applied to the Brazilian patients suffering from LBP. The total score is the sum of the points, ranging from 0 to 24 points. The higher questions sum indicates greater disability. However, a score greater than 14 , characterizes the presence of significant disability resulting from LBP.

\section{Electromyography (EMG)}

For the acquisition of the EMG signal, it was used an portable equipment EMG (EMG System do Brasil Ltda.) with 8 channels and active-type surface electrodes, bipolar and differential, connected to the Windaq signal acquisition software, the signal being passed through a high pass filter $20-500 \mathrm{~Hz}$ bandwidth, amplified 1,000 times and converted by A/D plate with $2000 \mathrm{~Hz}$ sampling frequency for each channel and with an input variation of $5 \mathrm{mV}^{(13)}$.

For carrying out the procedures subjects remained in a prone position, at rest, with two electrodes in the gluteus maximum muscle right and left gluteus right and left Medium with $2 \mathrm{~cm}$ distance from the point engine. The collection time of EMG activity was 1 minute in each collection, before and after the application of the maneuvers.

\section{Stabilometry}

The stabilometry was evaluated through a pressure platform (Model S-Plate, Medicapteurs, France). The participants were placed on the platform according to the standards difined by the Association Francaise de Posturologie (AFP) ${ }^{(14)}$. In the standard condition, they remain as still as possible in bipedal support, barefoot, with the heels with two centimeters between each other and the feet in 30 degrees rotation; looking at a fixed target 100 centimeters away positioned at the height of the gaze of the individual, with arms along the body and supervised by a therapist.

The stabilometry parameters analyzed were: pressure center (ellipse area of $90 \%$ confidence), mean pressure position on the $X$ and $Y$ axis, and the medial-lateral $(\mathrm{ML})$ and anteroposterior (AP) velocities. The test duration was 60 seconds. The first ten seconds were excluded to eliminate transient phenomena ${ }^{(15,16)}$.

\section{Heart rate variability (HRV)}

Before and after manual neural stimulation the autonomic nervous system (ANS), sympathetic and parasympathetic activity, it was evaluated by heart rate variability (HRV), with the aid of Nerve-Express ${ }^{\circledR}$ Software (Heart Rhythm Instruments, Metuchen, NJ, USA) ${ }^{(17)}$. Data acquisition was performed by a transmitter belt, placed on the chest of the participant at xiphoid process, and a heart rate receptor attached to the waist and coupled to a computer for processing and capturing the data.
The individual started the dorsal decubitus test on a couch and after 192 beats (RR interval) the subject was requested to stand up, standing facing a target fixed one meter away and at the height of the gaze, remaining in this position until completing RR 448, which represents approximately five minutes. The record approximately 1 minute was needed to evaluate the high frequency components of HRV whereas approximately 2 minutes were necessary for recording the low frequency components. In order to standardize the procedure, five minutes registration was carried out according to HRV standardized measures of the European Society of Cardiology and The North American Society of Pacing and Electrophysiology. All evaluations were performed in a controlled environment (light, temperature and sound). The HRV signals were compiled with the routines of MATLAB (The Mathworks, Natick, MA, USA) and analyzed in both areas of frequency and time, through the Kubios HRV software version 1.1 (Biosignal Analysis and Medical Imaging Group, Kuopio, Finland). The frequency bands that were analyzed in this study are in accordance with the guidelines previously published by the American Heart Association which indicate the recommendations for HRV measuring and interpretations (Task Force of the European Society of Cardiology and the North American Society of Pacing and Electrophysiology) ${ }^{(18)}$

The variables used in the time domain: Mean RR (average values of $\mathrm{NN}$ intervals in a period of time), $\mathrm{RH}$ intervals (heartbeats/min) SDNN (standard deviation of NN interval - an estimate of the total HRV) rMSSD (Root Mean Square of the Successive Differences of NN intervals - parasympathetic marker), these variables were measured in the supine position; and the frequency domain (contributed to understanding the autonomic background fluctuations in RR intervals in heart rate register) were measured in both lying position and standing, and the variables analyzed are included: Low Frequency (LF) which is modulated by both the sympathetic and parasympathetic activities) and high frequency (HF) modulated exclusively by parasympathetic activities. The LF/HF ratio was considered as a marker of the sympatho-vagal balance ${ }^{(18)}$.

\section{Statistical analysis}

The data were arranged in spreadsheets and analyzed by GraphPad Prism 5.0 software. For the analysis of normal distribution, the Shapiro-Wilk test was used. Once verified the normality of the samples, the Student's t test was used for one-tailed parametric samples, with significance level $p \leq 0.05$. For the non-parametric samples the Wilcoxon post-test was used.

\section{RESULTS}

The age ranged from 20 to 24 years, an average of 21.85 years, and weight presented variance $48-73 \mathrm{~kg}$, with an average of $55.42 \mathrm{~kg}$.

In figure $2 \mathrm{~A}$ are arranged the average values obtained by the analysis of the numerical pain scale for pre- and post-technique, 
which were respectively: $2.714 \pm 1.380$ and $1.357 \pm 1.180$. In the graph analysis, it is possible be noticed that there was a decrease in the average pain threshold of the patients after being submitted to the technique, whereas in the statistical analysis there was a significant difference between the groups with $\mathrm{p}=0.0264$.

In figure $2 \mathrm{~B}$ are presented the average values obtained by the analysis Schöber test, respectively: $21.93 \pm 1.367$ and $22.43 \pm 1.305$. A slight increase in the degree of lumbosacral mobility is noticed in the patients after being submitted to the technique. In the statistical analysis, there was a significant difference between the groups with $p=0.0191$.

In relation to the Wells test, a significant value of $p=0.0313$ was obtained compared to the mean value before the technique $(21,14)$ and after $(23,85)$, indicating improvement in flexibility after the technique application (Figure $2 \mathrm{C}$ ).

In Figure 2D the mean values are contained by the questionnaire analysis of functional disability Rolland-Morris pre-technique and 30 days after treatment, which were respectively $6.111 \pm 3.695$ and $3 \pm 1.333$. In the analysis of the graph it is possible to observe that there was a decrease in the functional disability of the participants after being submitted to the technique.

In the EMG analysis, the stimulation threshold (mVolts) of the gluteus maximus and medius muscles were verified at the pre- and post-technique moments. Figure 3 shows the mean values of the electromyography of the gluteus maximus and medius muscles of the right and left lower limbs before and after the application of NPT (NPT). Statistical analysis using One-Way and Tukey's post-test it was obtained a significant value of $p=0.0205$.

Regarding the stabilometry, the following variables were analyzed: lateral deviation and anteroposterior deviation at the pre-technical and post-technical moments.

In figure 4 , there is the representation of the average values obtained by analyzing the anteroposterior deviation
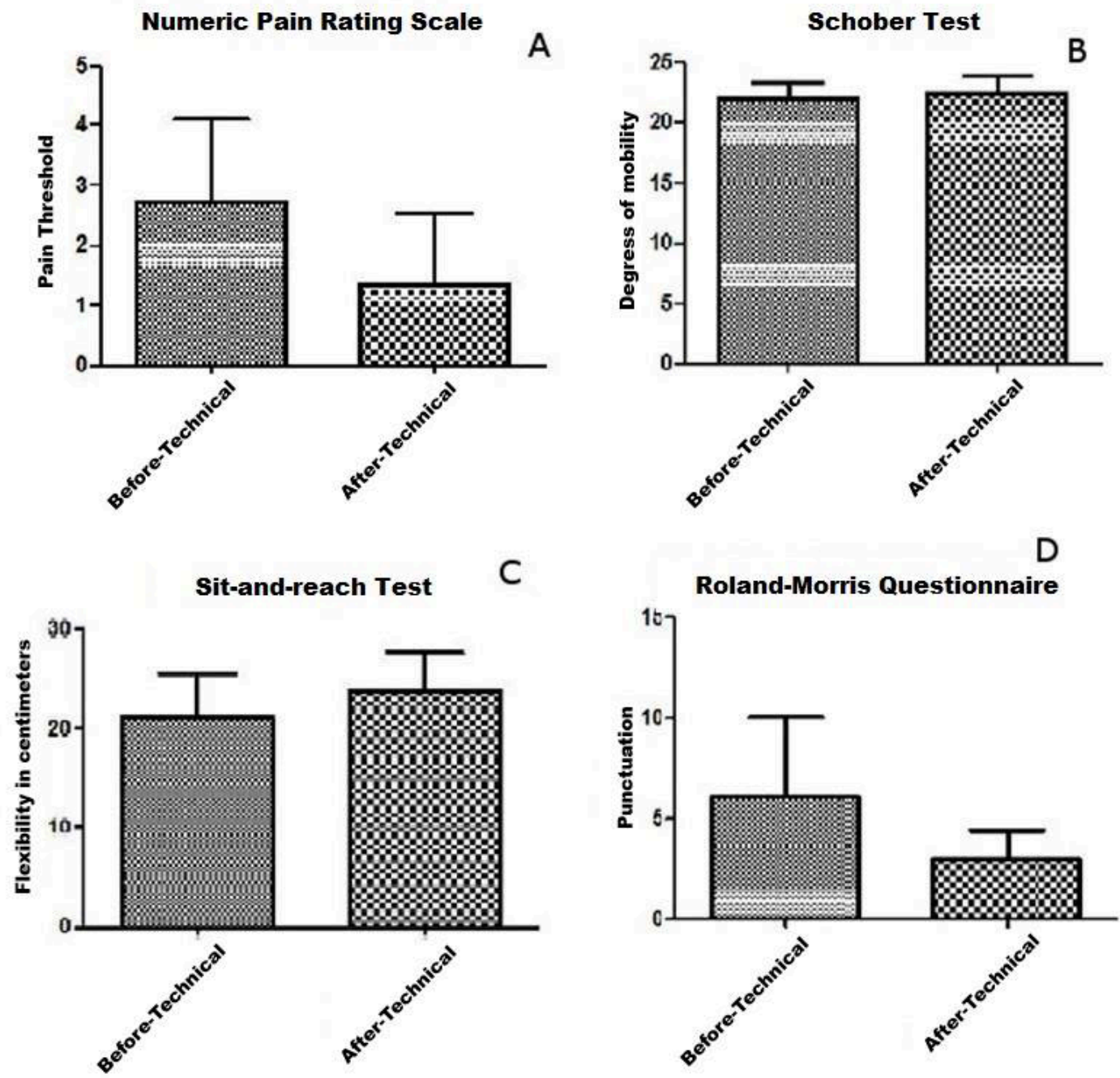

Figure 2. Mean values for pain, flexibility tests and functional questionnaire. 
technique for pre-and post-technique, which were respectively $2,556 \pm 2,282$ and $1,899 \pm 3,819$. In the analysis of the graph it is possible to note that there was a decrease in the mean oscillation of the patients after being submitted to the technique, however there were no statistically significant results.

It is possible to note that from the representative values obtained by the analysis of the lateral for pre-and post-technique, which were respectively: $-2.871 \pm 2.654$ and $0.02344 \pm 2,911$. In the analysis of the graph it is possible to noted that, regarding the anteroposterior deviation, there was also a decrease in the mean oscillation of the patients after being

\section{RMS Values of Electromyography}

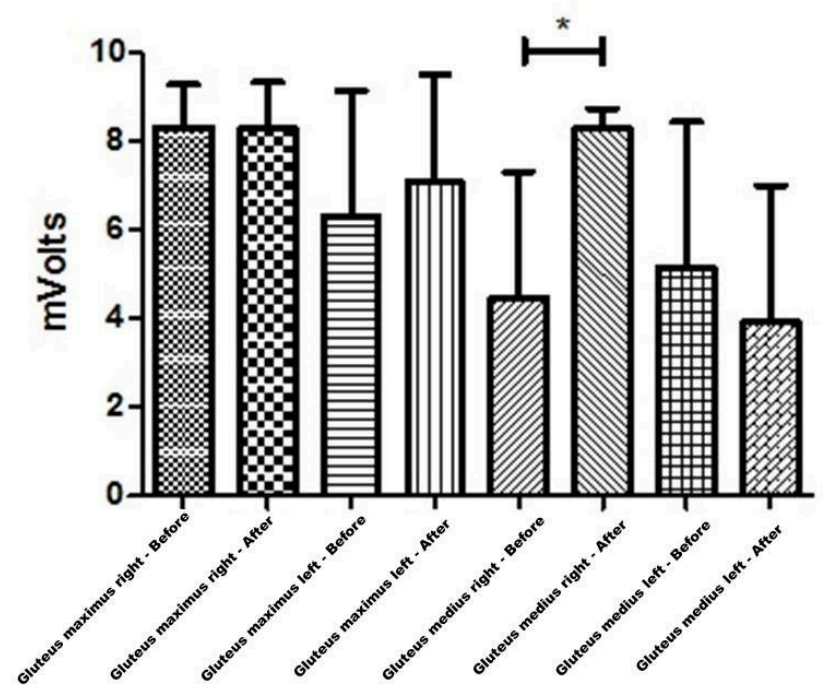

Figure 3. Electromyographic analysis of Gluteus Maximus and Medius muscles before and after the application of Neurosensory Postural Therapy. submitted to the technique, with significant statistical results $\mathrm{p}<0.0001$.

In the Figure $5 \mathrm{C}$ there are the mean values of pre/post immediate technical application and after 30 days from the application regarding the heart rate variability, whose values are respectively $1.541 \pm 0.7042 \mathrm{~ms} ; 1.122 \pm 0.6289 \mathrm{~ms}$ and $0.7471 \pm 0.2041 \mathrm{~ms}$ of the HF/LF ratio. It found a significance of $p=0.0313$. Therefore, treatment with SNP provided a balance between the sympathetic and parasympathetic nervous system with improved effect after application of the technique and after 30 days.

After the verification, it was observed that the treatment with NPT promoted an improvement in the action of the cardiovascular system by generating a faster chronotropic response. The mean values of the chronotropic reaction before and after the application of the technique were, respectively, $0.704 \pm 0.06703 \mathrm{~ms}$ and $0.656 \pm 0.05641 \mathrm{~ms}$. In the paired Student's T-test, a significance level of $p=0.0009$ was observed.

The interpretations of the physiological states of the nervous system are shown in figure 5 , where A corresponds to the pre-application, B post-application and C corresponds to 30 days of application of the technique.

\section{DISCUSSION}

Clinical Postural Therapy is based on the principle that the body is constantly maintaining posture, which through its sensory inputs called "outputs" (oculomotricity, the vestibule and proprioception), the "command center", i.e., the brain receives information as the posture is and body position in relation to space, and by analyzing this information, it decides what should be done, and depending on the case, it sends a response to the postural tonic system for a modification of its standard to generate postural stability ${ }^{(5)}$.

In pathological processes, mainly chronic processes, this modulation is altered, and thus the whole process of sending sensory information is deficient, therefore generating
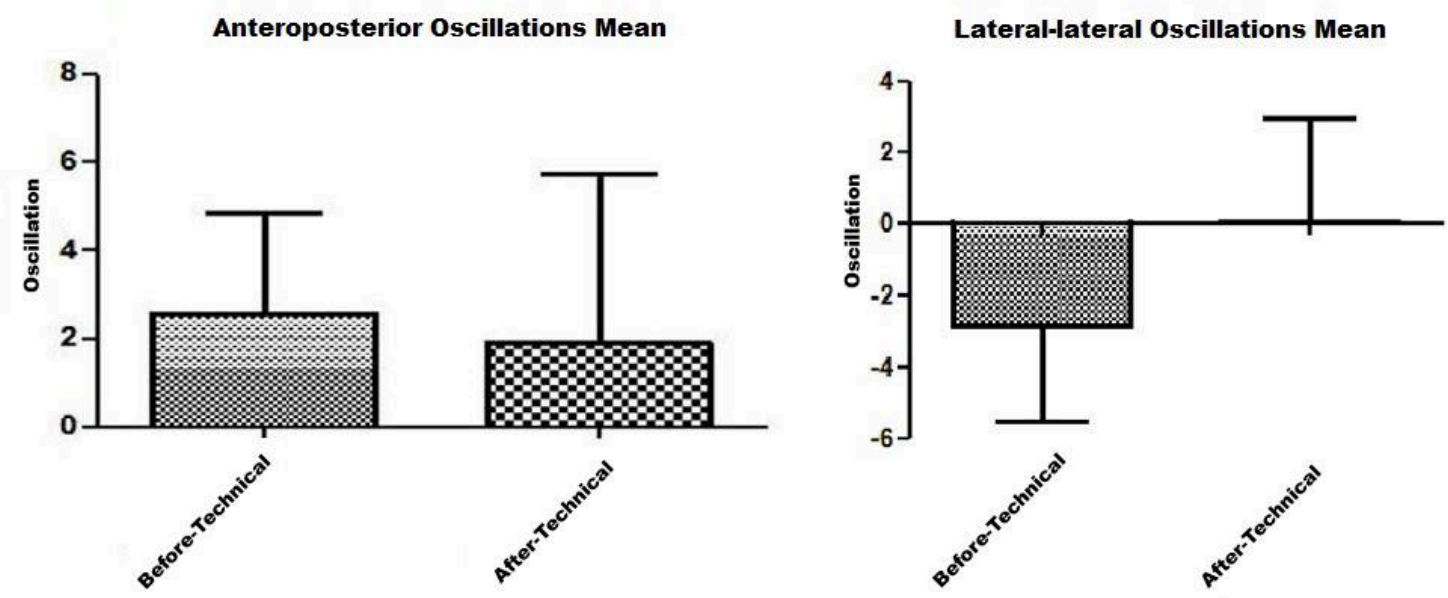

Figure 4. Stabilometry analysis according the predominance for the lateral deviation. 

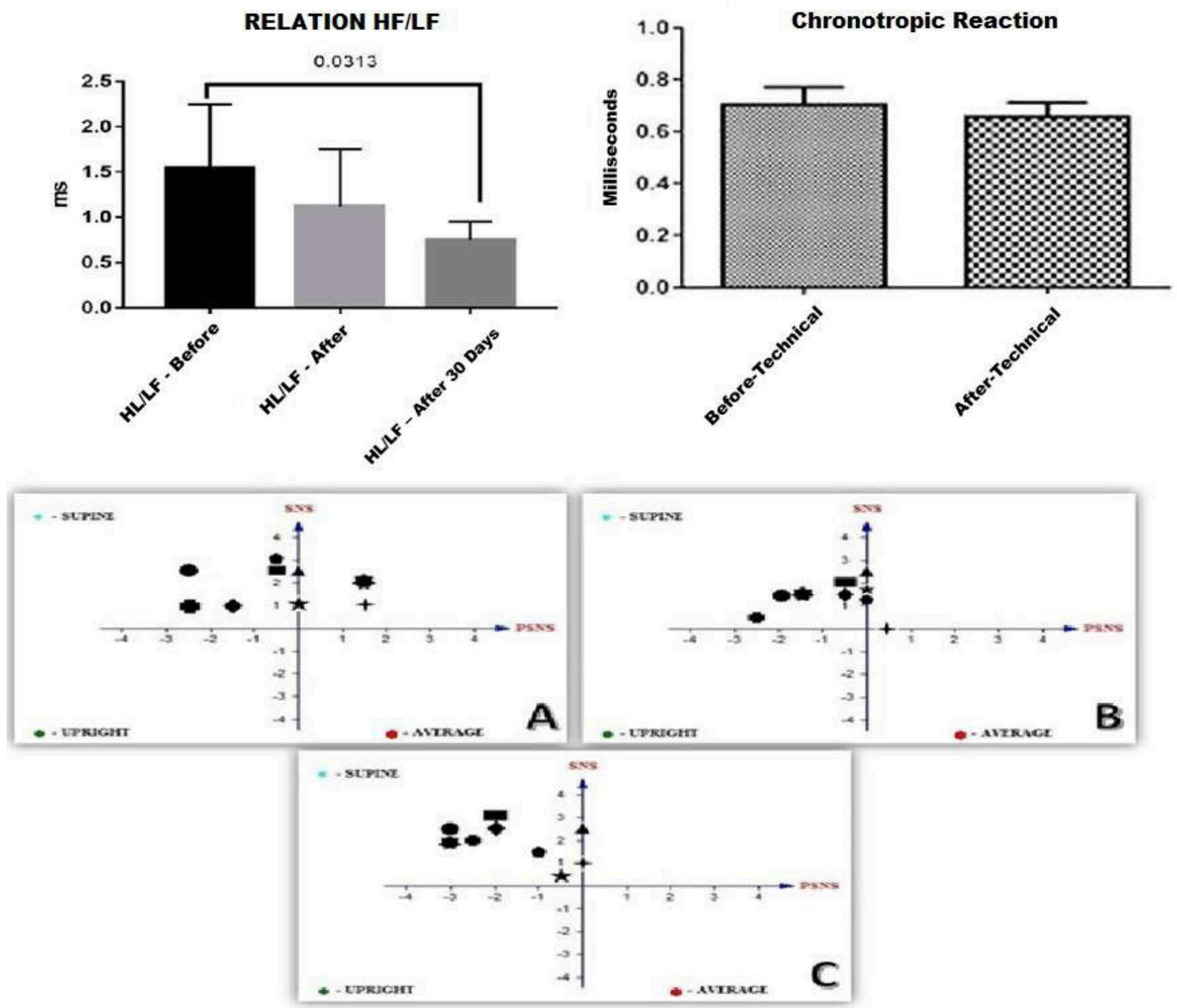

Figure 5. Relationship of high and low frequency. Distribution of the physiological states of the treated individuals and the interpretation of the physiological states of the autonomic nervous system.

a neuromuscular imbalance, and consequently, postural alterations, alterations of balance and facilities of pain processes.

Thus, the NPT proposes an intervention in this process, where through neural manual, light, precise and fast stimuli, the body receives this information and modulates the appropriate tonic response, influencing the postural regulation system to reprogram the posture, and relieve pain ${ }^{(5)}$.

Although there are few studies which investigate the effects of NPT, the technique may be compared to other techniques described in the literature and which have positive effects on the changes of patients with chronic LBP, for example, neural mobilization, manipulations or Neuromuscular balance techniques.
Santos and Domingues (2008) ${ }^{(19)}$ evaluated 10 women aged between 17 and 40, which were submitted to the hamstring shortening (HS) in three stages. The first phase consisted of an initial evaluation; the second was the application of the neural mobilization and the last was the reevaluation. As a result, they observed that all the volunteers showed a significant improvement between the evaluation before and after the neural mobilization application, and the right lower limb obtained a greater mean difference in the HS stretches and the lower limb showed a greater restriction in hip flexion, however the improvement in the stretching and gain of ROM in the hip flexion were similar in both lower limbs, so it was concluded that the mobilization technique is effective due to the average gain of 22.5을 amplitude. 
In present study, it was observed a significant improvement in mobility by relaxation of the lumbosacral posterior thigh muscles, showing that neural stimulation restores movement and elasticity of the nervous system and consequently it normalizes adjacent neural structures and functions which they are attached.

Bertolini et al. (2009)(20) evaluated the effects of the neural mobilization (saturation) and static elongation at sciatica induced nerve compression in the right member in 23 Wistar rats, in which they were divided into three groups: no intervention, static stretching and mobilizing neural. To evaluate the pain, they underwent the functional incapacitation test, where the animals were placed on a rotating metal cylinder using metal boots, and the right paw elevation time was measured. In the mobilization group, they performed 30 passive planting and dorsiflexion movements of the right limb for 1 minute, with the animal in dorsal decubitus, flexed hip and maximal extension of the knee. They concluded that reduction of pain occurred both with static stretching as with neural mobilization, with the mobilization results more significant. In the present study, by observing the results obtained in the visual analogue scale (VAS), there was a decrease in pain, consequently a change in the pain threshold.

Sohn et al. 2013 ${ }^{(21)}$ studied the effect of chronic lower back pain postural balance and stability. The sample consisted of a control group (healthy individuals) and a group of individuals with lumbar pain, and through stabilometric tests, it was possible to verify that individuals with lumbar pain processes had lower stability and postural control when compared to healthy individuals. For the present study, we chose to use the stabilometry to quantify the body oscillation of the individuals, both in the anteroposterior and lateral directions. There was an improvement in postural stability and activity of the stabilizing muscles of the hip (gluteus maximus and gluteus medius).

Neural mobilization is an established and efficient technique to promote flexibility, reduction of lumbar spine pain processes, and improvement of postural control. Machado and Bigolin (2010) $)^{(22)}$, demonstrated the efficacy of the technique to compare it with the stretching technique in patients with chronic LBP, where there was a greater technical efficiency as much flexibility as pain in these individuals.

The NPT acts similarly, where through manual neural stimuli, it occurs the called "neural saturation", where the digital pressure on the nerve would lead to a vibration effect induced by the rapid withdrawal of the finger, and it would saturate the neural mechanoreceptors surpassing its maximum threshold and return the nerve to its physiological and neurodynamics excitability, contributed for better effectiveness of sensory responses. In the present study, it may be verified that the technique was capable of modulating and restoring the neurodynamic responses of the gluteal nerve.

Véras et al. 2012 ${ }^{(23)}$ used the electromyography to verify the effects of the technique on muscle activity and found that patients undergoing neural mobilization technique achieved improvement in EMG function and strength levels by reducing the degree of disability and pain.

Pinto et al. (2010) ${ }^{(24)}$ investigated the effect of muscular dynamics rehabilitation in postural balance and reduction of back pain in 82 industrial workers. Individuals were divided into experimental and control groups. The procedures for evaluation were: LBP (Borg scale) and postural balance (Stabilometric and posturometric pedia). The intervention by muscular dynamics rehabilitation had the following protocols: 20 minutes, 2 times per week for 12 weeks. As results, there was a significant improvement in lumbar pain and postural balance.

The application of the technique according to the proposed study decreased the lateral and anteroposterior deviation, however only the lateral showed significance, so the technique re-adjusted the muscle tone of the gluteus medius muscle, which it is responsible for the control of the hip in the sagittal plane.

The study by Gockel et al. (2008) ${ }^{(25)}$ it was evaluated the association of cardiovascular autonomic balance to the perceived pain and functional impairment in patients with chronic LBP, evaluated by the Oswestry questionnaire. The authors observed that HRV is lower in patients with chronic LBP and with moderate functional impairment compared to patients with minimal levels of functional damage, and that the levels of suffering, pain and disability may cause an increase in sympathetic activity.

In the present study, it was observed that most of the patients before the intervention procedure were among one of three categories of the physiological stage of the nervous system which indicate the occurrence of the increase/prevalence of the sympathetic nervous system activity and decrease of the parasympathetic nervous system activity.

Mostoufi et al. (2012) ${ }^{(26)}$ examined the HRV in a sample of 84 patients with chronic pain. They observed that a better functioning of physical health is associated with a higher overall HRV. The increase in pain anxiety is associated with a low frequency of HRV. Painful sensations were negatively associated with the ratio $\mathrm{HF} / \mathrm{LF}$, where as they occur more affective responses to pain occurs less dominance of the sympathetic nervous system. And factors such as operation of physical health, anxiety, pain and being sensations are related to HRV.

In this study, it was observed that there was an improvement in the ratio $\mathrm{HF} / \mathrm{LF}$, where the intervention provided a balance between the sympathetic and parasympathetic nervous system; in the three stages of care is observed an increase in parasympathetic activity and a lower prevalence of the sympathetic nervous system.

Stefane et al. (2013) ${ }^{(27)}$ evaluated the perception of pain, disability, and quality of life in 97 patients with chronic LBP, the 
disability mean was 14.4; pain intensity during the interview, 5.4; and quality of life 48.1 points. The physical domain of quality of life was the most affected, 44.1 points, thus showing that LBP generates disability and, consequently impairing the quality of life of the individuals. The present study also noted a decrease of functional failure of patients after application of the technique.

As a limitation of the study, there was a large sample loss and the exclusion of the 30 days group in some variables, because they were evaluated on different days and not all patients returned for re-application of the technique after 30 days, thus only the inability Rolland-Morris and the Variability of Heart Rate Questionnaires have been redone.

In clinical practice, this technique is a supporting intervention in the treatment of LBP of musculoskeletal order. Other interventions such as the ergonomic correction, the muscle-building, among others, should be related to the treatment of NPT.

\section{CONCLUSION}

It was concluded that the NPT technique is effective as adjunctive treatment in patients with chronic LBP by promoting reduction of pain symptoms, improving mobility, flexibility, and to promote improvement in functional capacity, stability body, heart rate variability and chronotropic response.

\section{AUTHORS' CONTRIBUTIONS}

PV demonstrated the application of the technique and read and approved the final version of the manuscript, LAC prepared the manuscript and read and approved the final version of the manuscript, RBP prepared the manuscript and read and approved the final version of the manuscript, LGR performed the data collection (technical application), analysis and interpretation of data and prepared the manuscript (introduction, results and discussion), APH performed the data collection (electromyography and heart rate variability), analysis and data interpretation and compiled the manuscript (results and discussion), MPPR performed the data collection (Free and Clarified Consent Term, numeric scale of pain, personal data, Schöber Test and Wells bench), analysis and interpretation of data and prepared the manuscript (results and discussion), TBO performed the data collection (Questionnaire Rolland-Morris failure and heart rate variability), analysis and interpretation of data and prepared the manuscript (results), JCG performed the data collection (stabilometry), analysis and interpretation of the data and produced manuscript (Materials and Methods, Results and Discussion) and submitted the article, IIK performed the statistical analysis, analysis and interpretation of data, supervised the research group, developed the manuscript (materials and methods, results and conclusion) and read and approve the final version of the manuscript, MCP performed the statistical analysis and read and approve the final version of the manuscript, ASIS performed the analysis and interpretation of data and read and approved the final version of the manuscript.

\section{CONFLICTS OF INTEREST}

The author(s) declare that they have no competing interests.

\section{AUTHOR DETAILS}

${ }^{1}$ Professor of the Universidade Estadual do Centro-Oeste (UNICENTRO), Guarapuava (PR), Brazil. School of Manual and Postural Therapy, Londrina (PR), Brazil.

3 Professor at the Universidade Estadual do Centro-Oeste (UNICENTRO), Guarapuava (PR), Brazil

\section{REFERENCES}

1. Imamura ST, Kaziyama HHS, Imamura M. Lombalgia. Rev Med. 2001;80(2):375-90.

2. Rodrigues ST, De Oliveira JQ, De Matos LK. Effects of pilates method in LBP. Ter Man. 2014;12:392-99.

3. Gagey PM, Weber B. Posturologie. Régulation, dérèglements de la station debout. Paris: Ed Masson; 1999.

4. Chou R, Qaseem A, Snow V, Casey D, Cross TJR, Shekelle P, et al. Diagnosis and treatment of LBP: a joint clinical practice guideline from the American College of Physicians and the American Pain Society. Ann Intern Med. 2007;147:478-91.

5. Villeneuve P. Dysfonctions neurales, algies posturales et neurostimulations manuelles. Apport du traitement manuel neural dans la douleur chronique. Clinique et traitement, Méthodologie illustrée avec le nerf fibulaire profound. La Rev de l'ost. 2012;42:35-42.

6. Ray B, D'Souza AS, Saxena A, Nayak D, Sushman RK, Shetty P, et al. Morphology of the superior gluteal nerve: a study in adult human cadavers. Bratisl Lek Listy. 2013; 114:409-12.

7. Standring S. Gray's anatomy. 40th ed. England. Churchill Livingstone Elsevier; 2008.

8. Ling ZX, Kumar VP. The course of the inferior gluteal nerve in the posterior approach to the hip. J Bone Joint Surg Am. 2006;88:1580-3.

9. Goertz CM, Pohlman KA, Vining RD, Brantingham JW, Long CR. Patientcentered outcomes of high-velocity, low-amplitude spinal manipulation for LBP: a systematic review. J Electr and Kinesiol. 2012;22(5):670-91.

10. Macedo RB. Quality of life, school backpack weight, and nonspecific LBP in children and adolescents. J Ped. 2015;91(3):263-9. [Versão em Português].

11. Barboza NM, Floriano EN, Motter BL, Silva FCD, Santos SMS. Efetividade da fisioterapia associada à dança em idosos saudáveis: ensaio clínico aleatório. Rev Bras Geriat e Geront. 2014;17(1):87-98.

12. Nusbaum L, Natour J, Ferraz MB, Goldenberg J. Translation, adaptation and validation of the roland-morris questionnaire - Brazil rolandmorris. Braz J Med Biol Res. 2001;34:203-10.

13. Politti F, Palomari ET, Furtado R. Análise eletromiográfica e da força do músculo deltóide em indivíduos com síndrome do impacto do ombro. Fisiot e Pesq. 2006;13(3): 24-33.

14. Bizzo G, Guillet N, Patat A, Gagey PM. Specifications for building a vertical force platform designed for clinical stabilometry. Med Biol Eng Comput. 1985;423:74-476.

15. Kapteyn TS, Bles W, Njiokiktjien $\mathrm{CH}$, Kodde L, Massen $\mathrm{CH}$, Mol JMF. Standardization in platform stabilometry being a part of posturography. Agressologie. 1983;24:321-6.

16. Scoppa F, Capra R, Gallamini M, Shiffer R. Clinical stabilometry standardization: basic definitions - acquisition interval - sampling frequency. Gait Posture. 2013;37: 290-2.

17. Kerppers II, Arisawa EAL, Oliveira LVF, Sampaio LMM, Oliveira CS. Heart rate variability in individuals with cerebral palsy. Arch Med Sci. 2009;5(1):45-50.

18. Vanderlei LCM, Silva RA, Pastre CM, Azevedo FM, Godoy MF. Comparison of the Polar S810i monitor and the ECG for the analysis of heart rate variability in the time and frequency domains. Braz J Med Biol Res. 2008;41(10):854-9.

19. Dos Santos CF, Domingues CA. Avaliação pré e pós-mobilização neural para ganho de ADM em flexão do quadril por meio do alongamento dos isquiotibiais. ConScientiae Saúde. 2008;7(4):487-95.

20. Bertolini GRF, Silva TC, Trindade DL, Ciena AP, Carvalho AR. Neural mobilization and static stretching in an experimental sciatica model: an experimental study. Rev Bras Fisioter. 2009;3(6):493-8.

21. Sohn MK, Lee SS, Song HT. Effects of acute LBP on postural control. Ann Rehabil Med. 2013;37(1):17-25. 
22. Machado GF, Bigolin SE. Estudo comparativo de casos entre a mobilização neural e um programa de alongamento muscular em lombálgicos crônicos. Fisioter Mov. 2010; 3(4):545-54.

23. Véras LST, Vale RGS, De Mello DB, De Castro JAF, Lima V, Trott A, et al. Electromyography function, disability degree, and pain in leprosy patients undergoing neural mobilization treatment. Rev Socied Bras Med Tropic. 2012;45(1):83-8.

24. Pinto FM, Bacelar SC, Da Silva LB, Bertoni G, Knoplich J, Dantas EHM. Reeducação Dinâmica Muscular no Equilíbrio Postural e na redução da lombalgia em trabalhadores industriais. Mundo Saúde. 2010;34(2):92-199.
25. Gockel M, Lindholm H, Niemistö L, Hurri H. Perceived disability but not pain is connected with autonomic nervous function among patients with chronic LBP. J. Rehabil Med. 2008;40:355-8.

26. Mostoufi SM, Afari N, Ahumada SM, Reis V, Wetherell JL. Health and distress predictors of heart rate variability in fibromyalgia and other forms of chronic pain. J. Psychosom Res. 2012;72(1):39-44

27. Stefane T, Santos AM, Marinovic A, Hortense P. Chronic LBP: pain intensity, disability and quality of life. Acta Paul Enferm. 2013;26(1):1420. 